\title{
A novel murine tryptase involved in blastocyst hatching and outgrowth
}

\author{
C. M. O'Sullivan*, S. L. Rancourt*, S. Y. Liu and D. E. Rancourt ${ }^{\dagger}$ \\ Southern Alberta Cancer Research Centre, Department of Biochemistry and Molecular \\ Biology, University of Calgary, Calgary, Alberta T2N 4N1, Canada
}

\begin{abstract}
Before implantation the blastocyst is maintained within a proteinaceous coat, the zona pellucida, which prevents polyspermy and ectopic pregnancy. An extracellular trypsin-like activity, which is necessary for hatching from the zona pellucida in vitro, is localized to the abembryonic pole of the blastocyst. Upon hatching, the extracellular matrix-degrading proteinases urokinase plasminogen activator (UPA) and matrix metalloproteinase 9 (MMP-9) are thought to promote blastocyst invasion. However, gene disruption experiments have demonstrated that uPA and MMP-9 are dispensable and, thus, that other key enzymes are involved in implantation. In this study, a novel implantation serine proteinase (ISP1) gene, which is distantly related to haematopoietic tryptases and represents
\end{abstract}

a novel branch of the $\mathrm{S} 1$ proteinase family, was cloned. ISP1 is expressed throughout morulae and blastocysts during hatching and outgrowth. Abrogation of ISP1 mRNA accumulation using antisense oligodeoxynucleotides disrupts blastocyst hatching and outgrowth in vitro. The results of this study indicate that the ISP1 gene probably encodes the long sought after 'hatching enzyme' that is localized to the abembryonic pole during hatching in vitro. ISP1 is the earliest embryo-specific proteinase to be expressed in implantation and may play a critical role in connecting embryo hatching to the establishment of implantation competence at the abembryonic pole of the blastocyst.

\section{Introduction}

Implantation involves an intricate co-ordination of endometrial and blastocyst factors for the correct attachment of the embryo and its subsequent controlled invasion into maternal deciduum (for review see Rinkenberger et al., 1997; Carson et al., 2000). Within the uterus, the blastocyst must shed the zona pellucida before fostering an intimate relationship with the maternal deciduum. Thinning of this proteinaceous structure precedes hatching and is thought to result from both internal pressures presented by the growth of the blastocyst and the presence of uterine and embryo-derived 'lysins' (Montag et al., 2000). In particular, an embryo-derived, extracellular 'trypsin-like' activity is crucial for the completion of hatching in vitro and has been localized histochemically to the abembryonic pole where hatching is initiated (Perona and Wassarman, 1986; Sawada et al., 1990; Hwang et al., 2000). This apical surface is also the first to become adhesive in utero and orients the blastocyst within the implantation chamber (Kirby et al., 1967).

On release from the zona pellucida, several extracellular matrix proteins promote blastocyst attachment and outgrowth in vitro (Carson et al., 1993). For example, heparin

*Both authors contributed equally to this work

${ }^{+}$Correspondence

Email: rancourt@acs.ucalgary.ca sulphate proteoglycan occurs on the surface of abembryonic trophoblasts. Attachment and outgrowth of blastocysts in vitro is inhibited by heparinase or soluble heparin (Farach et al., 1987). Localized heparin sulphate may also facilitate the embryo-uterine dialogue and blastocyst implantation competence through the localized secretion of maternal heparin binding-epidermal growth factor (HBEGF). Secreted HB-EGF promotes blastocyst hatching and outgrowth in vitro (Das et al., 1994). In turn, a transmembrane form of HB-EGF, which is expressed on the surface of uterine epithelia, may mediate blastocyst adherence through this localized heparin sulphate proteoglycan and the apically expressed EGF receptor, ErbB4 (Raab et al., 1996; Paria et al., 1999; Wang et al., 2000).

The embryo-uterine interaction and the eventual integration of the embryo into the maternal crypt are also mediated by extracellular matrix-degrading proteinases that are secreted by the invading trophoblasts. However, the nature of a potential implantation proteinase cascade is poorly understood. On day 5 of embryogenesis, blastocystic urokinase plasminogen activator (UPA) occupies receptors on the trophoblast cell surface, where it is thought to activate ubiquitous plasminogen locally and to initiate decidual extracellular matrix degradation (Teesalu et al., 1996). Plasmin is also thought to activate trophoblastic matrix metalloproteinase 9 (MMP-9), a matrix metalloproteinase that cleaves several extracellular matrix components and which is thought to give the embryo its invasive character (Harvey et al., 1995; Alexander et al., 1996). 
Inhibitor studies indicate that both UPA and MMP-9 are likely to play principal roles in blastocyst outgrowth during implantation (Behrendtsen et al., 1992; Werb et al., 1992). In sharp contrast, targeted mutagenesis studies have indicated that either proteinase is dispensable in implantation (Carmeliet et al., 1994; Vu et al., 1998). These latter observations question the potential interaction of the uPA/ plasmin and MMP-9 proteinases within the presumed implantation proteinase cascade and indicate that other proteinases may be important in implantation. Some of these proteinases have started to be identified (Lefebvre et al., 1995; Afonso et al., 1997; Vu et al., 1997); however, we sought to identify additional serine proteinases that may be involved in implantation. Here, the cloning of a novel 'tryptase-like' implantation serine proteinase (ISP1) is described and it is proposed that the ISP1 gene encodes the long sought after 'trypsin-like' hatching enzyme. In addition, it is demonstrated that abrogation of ISP1 gene expression prevents both hatching and blastocyst outgrowth in vitro, thereby indicating that this hatching enzyme may also play an important early role in the initiation of implantation.

\section{Materials and Methods}

\section{Animals and treatments}

CD1 mice were obtained at the age of 6-7 weeks from Charles River Canada (St Constant, PQ) and were maintained in a standard laboratory animal facility with controlled temperature $\left(20^{\circ} \mathrm{C}\right)$ and lighting (lights on between 07:00 $\mathrm{h}$ and 19:00 h). The maintenance and treatment of the animals were in full compliance with standard laboratory animal care protocols approved by the University of Calgary's Animal Care Committee.

Female mice were paired with adult males to obtain natural pregnancies and were checked once a day for the presence of a vaginal copulatory plug as an indication of mating. For embryo collection, day 0.5 corresponded to mid-day of the day on which a vaginal plug was detected. Pregnant dams were killed on a specific day of embryo development by cervical dislocation after which uteri and oviducts were removed surgically before isolation of embryos, either by dissection or flushing (Hogan et al., 1994).

\section{Embryo culture}

Morulae were collected from oviducts of superovulated dams on day 2.5 of pregnancy into M2 medium (Hogan et al., 1994). For hatching, morulae were cultured in microwells for approximately $24 \mathrm{~h}$ at $37^{\circ} \mathrm{C}, 5 \% \mathrm{CO}_{2}$ in air in KSOMaa medium (Erbach et al., 1994). In embryo outgrowth, hatched blastocysts were cultured for an additional $48 \mathrm{~h}$ at $37^{\circ} \mathrm{C}, 5 \% \mathrm{CO}_{2}$ in air in Dulbecco's modified Eagle's medium (DMEM) plus 5\% (v/v) fetal bovine serum on microwells coated with extracellular matrix derived from
$10 \%(\mathrm{v} / \mathrm{v})$ Triton-X100-treated mouse embryo fibroblasts (Behrendtsen et al., 1995).

\section{Preparation of embryo $R N A$}

Total RNA was collected from embryos plus deciduum (implantation sites on day 6.5 of embryo development), embryos (days 8.5, 11.5 and 13.5 of embryo development) and placentae (days 11.5 and 13.5 of embryo development) using Trizol (Life Technologies, Rockville, MD). Hatching blastocysts (100 at 50\% hatch (time at which $50 \%$ of embryos have hatched from their zona pellucida)) were collected by centrifugation at $3000 \mathrm{~g}$ for $5 \mathrm{~min}$ for Trizol RNA preparation. RNA from outgrowing blastocysts was collected by Trizol lysis directly in microwells. Poly $(A)^{+}$ RNA was enriched from day 6.5 embryo plus deciduum total RNA using oligo (dT) cellulose chromatography (Sambrook et al., 1989).

\section{Serine proteinase active site $R T-P C R$ cloning}

Total RNA $(1 \mu \mathrm{g})$ from day 6.5 embryo plus deciduum was reverse transcribed using Superscript II (Life Technologies) and was used as a template for active site PCR using degenerate His (5'-CGGAATTCTI(ACT)TI(AT)(GC)IGC(AGCT)G(AGCT)CA(CT)TG-3') and Ser (5'-GCGGATCCA(AG)IGGICCICC(ACGT)(CG)(TA)(AG)TC(AGCT)CC-3') active site primers (Prendergast et al., 1991). Each $12.5 \mu \mathrm{l}$ PCR reaction used $0.5 \mu \mathrm{l}$ cDNA in $10 \mathrm{mmol}$ Tris- $\mathrm{HCl} \mathrm{I-1,} \mathrm{pH}$ 9.0, $50 \mathrm{mmol} \mathrm{KCl} \mathrm{I-1}, 1.5 \mathrm{mmol} \mathrm{MgCl}_{2} \mathrm{I}^{-1}, 130 \mu \mathrm{mol}$ dNTPs ${ }^{-1}$, $1 \mu \mathrm{mol} \mathrm{I}{ }^{-1}$ each primer and $1 \mathrm{U}$ Taq polymerase (Amersham Pharmacia, Piscataway, NJ). Forty rounds of thermal cycling consisted of $1 \mathrm{~min}$ at $94^{\circ} \mathrm{C}, 2 \mathrm{~min}$ at $55^{\circ} \mathrm{C}$ and $2 \mathrm{~min}$ at $72^{\circ} \mathrm{C}$. The amplification products were precipitated with ethanol, cleaved at flanking 5' EcoRI and 3' BamHI sites designed in the primer ends, eluted from a $1 \%(\mathrm{w} / \mathrm{v})$ agarose gel and cloned into EcoRl/BamHI cut pBluescript $\mathrm{KS}^{+}$ (Stratagene, La Jolla, CA). The inserts of individual clones were screened by restriction analysis (Sambrook et al., 1989), dye-terminator sequenced (Applied Biosystems, Foster City, CA) and compared with the Genbank sequence database using the BLAST program provided by the NCBI network server (Altschul et al., 1997).

\section{Library construction, cDNA cloning and sequence analysis}

Poly $(\mathrm{A})^{+}$RNA from day 6.5 embryo plus deciduum $(10 \mu \mathrm{g})$ was converted to random- and oligo(dT)-primed double stranded cDNA using the SuperScript cDNA cloning kit (Life Technologies). Notl-EcoRI adapters were ligated to the cDNA; the adapted cDNA was size selected by gel exclusion chromatography using a Sephacryl S-500 HR column (Life Technologies) and excess linkers were removed using Gene Clean (Qbiogene, Carlsbad, CA). Adapted cDNA $(1 \mu \mathrm{g})$ was ligated with $5 \mu \mathrm{g}$ dephosphorylated EcoRI-cut $\lambda$ GT10 (Amersham Pharmacia) and packaged into phage using Gigapack Gold II (Stratagene, 
La Jolla, CA). Recombinant phages $\left(2 \times 10^{6}\right)$ were amplified on plates and the pooled lysates were frozen $\left(-80^{\circ} \mathrm{C}\right)$ in $7 \%$ ( $\mathrm{v} / \mathrm{v}$ ) dimethylsulphoxide (DMSO) (Sambrook et al., 1989).

A 478 bp ISP1 PCR sub-fragment was used to screen $5 \times 10^{5}$ plaques from this library and resulted in the identification of two cDNA clones bearing a $1.3 \mathrm{~kb}$ insertion. An internal BamHI site within the ISP1 CDNA clone permitted the directional cloning of 0.5 and $0.8 \mathrm{~kb}$ EcoRI-BamHI fragments into pBluescript $\mathrm{KS}^{+}$(Stratagene) for cycle sequencing (Applied Biosystems). The nucleotide sequence was translated into protein sequence using the Swiss Protein ExPAsy tool (http://expasy.cbr.nrc.ca/tools/ dna.html). Twelve serine proteinase peptides identified from a BLAST identity search were aligned with ISP1 using Clustal W (Higgins, 1994; http://dot.imgen.bcm.tmc.edu: 9331/multi-align/multi-align.html).

\section{Expression analysis}

Poly (A) ${ }^{+}$RNA from day 6.5 embryo plus deciduum $(5 \mu \mathrm{g})$ was subjected to electrophoresis through a $1.2 \%$ $(\mathrm{w} / \mathrm{v})$ formaldehyde-agarose gel alongside an RNA high molecular mass ladder (Life Technologies). After transfer to Hybond $\mathrm{N}^{+}$(Amersham Pharmacia), the membrane was probed with the $1.2 \mathrm{~kb}{ }^{32} \mathrm{P}$-labelled ISP1 cDNA fragment.

The presence of ISP1 transcripts in embryos and placentae was monitored using RT-PCR. Total RNA $(1 \mu \mathrm{g})$ was reverse transcribed and amplified using primers specific for ISP1 (ISP1 for: $_{\text {ing }}$ '-GGAGCAGGAACTTCTGAACA-3'; ISP1 $1_{\text {rev }}$ : 5' -GTCAAAGATGGCCACAGC-3') and forty rounds of thermal cycling $\left(1 \mathrm{~min}\right.$ at $94^{\circ} \mathrm{C}, 2 \mathrm{~min}$ at $60^{\circ} \mathrm{C}$ and $2 \mathrm{~min}$ at $72^{\circ} \mathrm{C}$ ). The RT-PCR amplification of GAPDH (as a control for mRNA loading) is described elsewhere (ArcellanaPanlilio and Schultz, 1993). The predicted 175 and 380 bp amplification products were separated on a $2 \%(\mathrm{w} / \mathrm{v})$ agarose gel.

Whole embryo RNA in situ hybridization using digoxigenin-labelled RNA probes was performed essentially as described by Rancourt and Rancourt (1997). The ISP1 probe comprised the 478 bp RT-PCR subclone in pBSKS ${ }^{+}$. The antisense probe was synthesized using T3 polymerase after plasmid linearization with EcoRI. The sense probe was synthesized using T7 polymerase after plasmid linearization with BamHI. All experiments were performed with the sense RNA probe in parallel to detect non-specific hybridization.

Histochemical staining of strypsin activity was performed essentially as outlined by Perona and Wassarman (1986). Embryos were collected as early blastocysts in M2 medium and were fixed lightly in $1.25 \%(\mathrm{w} / \mathrm{v})$ glutaraldehyde in $0.25 \mathrm{~mol}$ sucrose $\mathrm{I}^{-1}, 50 \mathrm{mmol}$ sodium phosphate $\mathrm{I}^{-1}$ $(\mathrm{pH} 7.5)$ for $5 \mathrm{~min}$ at $4^{\circ} \mathrm{C}$. After fixation, the blastocysts were placed in $50 \mathrm{mmol}$ sodium phosphate $\mathrm{I}^{-1}(\mathrm{pH} 7.5)$ containing the substrate $N$ - $\alpha$-benzoyl-DL-arginine $\beta$ napthylamide $\left(0.56 \mathrm{mmol} \mathrm{I}^{-1}\right.$; Sigma, St Louis, MO) and Fast Garnet GBC salt (1.86 mmol I-1; Sigma), were incubated for $5 \mathrm{~min}$ at room temperature and washed in $50 \mathrm{mmol}$ sodium phosphate $\mathrm{I}^{-1}$ ( $\left.\mathrm{pH} 7.5\right)$.

\section{Antisense oligodeoxynucleotide studies}

In antisense oligodeoxynucleotide studies, harvested blastocysts were placed in $0.001 \%(\mathrm{v} / \mathrm{v})$ L-alysophosphatidylcholine for $60 \mathrm{~s}$ (Jones et al., 1997) and were transferred to microdroplets equilibrated with $2.5 \mu \mathrm{mol} \mathrm{I}^{-1}$ or $5.0 \mu \mathrm{mol} \mathrm{I}^{-1}$ oligodeoxynucleotide or an equal volume of $\mathrm{H}_{2} \mathrm{O}$ (Behrendtsen et al., 1995). Two antisense oligodeoxynucleotides were designed against regions surrounding the initiation codon of ISP1: AS1 (5'-TCTAACTACCGTCTAACAACG-3') situated upstream and AS2 (5'-GAACTCTTCTAACTACCGTCT-3') lying downstream. A control oligodeoxynucleotide, SS1, (5'-ACGGTAGTTAGAAGAGTTCT-3') represented the scrambled sense sequence surrounding the initiation codon. The oligodeoxynucleotides were designed using Oligo $^{\mathrm{TM}}$ software and were synthesized and purified by R. Pon (University of Calgary DNA Services, Calgary). Blastocysts were scored at 20,30, 40 and $60 \mathrm{~h}$ for progress in hatching. In these studies, both AS1 and AS2 interfered specifically with blastocyst hatching. However, AS1 was found to be more effective than AS2 and was used in all subsequent experiments. After $8 \mathrm{~h}$ of treatment, some blastocysts were assayed for the presence of ISP1 transcripts using RT-PCR. After $24 \mathrm{~h}$ of treatment, some blastocysts were assayed for strypsin activity using histochemical staining. In outgrowth studies, blastocysts were allowed to hatch and were then transferred to microdroplets equilibrated with oligodeoxynucleotide or water. Progress in outgrowth was monitored over a period of 5 days.

\section{Results}

\section{Encoding of a novel serine proteinase in implantation by the ISP1 gene}

Previous investigations of implantation, both in vivo and in vitro via blastocyst invasion assays, have indicated that a cascade of proteinases mediates the embryo-uterine interaction and the integration of the embryo into uterine deciduum during implantation. After evidence of genetic redundancy among implantation proteinases in the cascade was found, we initiated experiments to identify additional serine proteinases that may play a vital role in implantation. An active site RT-PCR strategy was followed (Prendergast et al., 1991) using RNA from day 6.5 implantation sites to reveal novel serine proteinase sub-cDNAs. At this stage in implantation the embryo is fully engaged in invading the deciduum. Amplification with degenerate primers surrounding the active site $\mathrm{His}$ and Ser regions gave rise to a number of fragments ranging in size from 0.4 to $0.5 \mathrm{~kb}$, consistent with the size of known serine proteinase His-Ser sub-cDNAs (Fig. 1a). Upon cloning and sequence characterization of these sub-cDNAs, a number of serine proteinases were identified including $\mathrm{UPA}$, tissue plasminogen activator (tPA), granzyme $D$, granzyme $F$ and two previously unidentified entities that we called ISPs (ISP1: present study; ISP2: O'Sullivan et al., in press). 
(a)

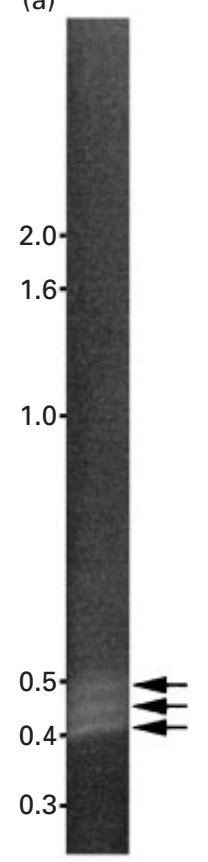

(b)

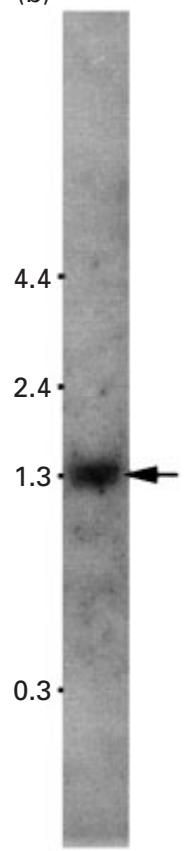

Fig. 1. Identification of the murine implantation serine proteinase 1 (ISP1) gene in mouse implantation site RNA. (a) Active site RT-PCR of day 6.5 embryo plus deciduum total RNA using S1 proteinase degenerate $\mathrm{His}$ and Ser oligonucleotide primers. Arrows indicate three PCR fragments obtained in the vicinity of $0.4-0.5 \mathrm{~kb}$. (b) Northern blot analysis of day 6.5 embryo plus deciduum poly $(\mathrm{A})^{+}$ RNA $(5 \mu \mathrm{g}$ ) revealed a mRNA species of $1.3 \mathrm{~kb}$ (arrow) when hybridized with a random prime-labelled $1.2 \mathrm{~kb}$ ISP1 cDNA clone.

\section{ISP1 represents a novel branch of the tryptase subfamily of $S 1$ proteinases}

Northern blot analysis of day 6.5 embryo plus deciduum poly (A)+ RNA using the 478 bp ISP1 sub-cDNA fragment indicated that the ISP1 transcript was $1.3 \mathrm{~kb}$ (Fig. 1b). A $1.2 \mathrm{~kb}$ full-length cDNA clone for ISP1 was isolated by generating and screening a day 6.5 mouse embryo plus deciduum cDNA library in $\lambda G T 10$. Sequence analysis of ISP1 revealed a predicted protein of 273 amino acids (Fig. 2). In BLAST identify searches (Altschul et al., 1997), it was found that ISP1 had a high degree of sequence similarity with the haematopoietic serine proteinases; the most similar was mouse mast cell protease 6 ( $45 \%$ amino acid identity; Lutzelschwab et al., 1997). Other mast cell proteases showed similar degrees of sequence identity. The next closest subfamilies contain chymotrypsins and elastases with approximately $38 \%$ shared amino acid identity. The relationship of ISP1 to the S1 peptidase family is clear as it shares the conserved $\mathrm{His}$ and Ser active site moieties (IHPQW and GDSGGPL), in addition to the common Nterminal sequence (IVVG) of mature tryptases (Fig. 2; Smyth et al., 1996).
ISP1 gene expression in preimplantation embryos and in vitro hatching and outgrowth

Given its sequence properties, we hypothesized that the ISP1 gene encodes the previously described trypsin-like protease, strypsin, involved in blastocyst hatching (Perona and Wassarman, 1986). Consistent with this hypothesis, RT-PCR confirmed that ISP1 is expressed during hatching and embryo outgrowth (Fig. 3a), and is detectable throughout all stages of preimplantation development from the zygote stage (Fig. 3b). Beyond implantation, ISP1 expression was detected faintly in day 11.5 and 13.5 placentae, but not in day $8.5,11.5$ or 13.5 embryos (S. L. Rancourt, unpublished). In agreement with our previous RT-PCR expression data, stronger in situ hybridization staining was observed in morulae compared with blastocysts (Fig. 4). In the blastocyst, ISP1 RNA expression was observed throughout the embryo. Here, equivalent staining of blastomeres was noted, although staining appeared more intense within the multilayer inner cell mass than in the monolayer trophoblast (Fig. 4d).

\section{Antisense abrogation of ISP1 gene expression and strypsin activity in blastocysts}

A possible role for ISP1 in hatching was examined by determining whether ISP1 mRNA could be reduced in blastocysts by treatment with antisense oligodeoxynucleotides (Behrendtsen et al., 1995; Jones et al., 1997) and result in an alteration of the hatching process (Fig. 5). Two antisense oligodeoxynucleotides were designed surrounding the initiation codon of ISP1 covering the regions immediately upstream (AS1) and downstream (AS2). A control oligodeoxynucleotide (SS1) represented the scrambled sense sequence surrounding the initiation codon. Blastocysts were scored at 20,30, 40 and $60 \mathrm{~h}$ for progress in hatching. In these studies, both AS1 and AS2 interfered specifically with blastocyst hatching (Table 1; Fig. 6). However, AS1 was found to be more effective than AS2 and was used in all subsequent experiments.

When blastocysts were treated with the AS1 oligodeoxynucleotide, it was determined that the accumulation of ISP1 transcripts was reduced at least 100 -fold after $8 \mathrm{~h}$ of culture (Fig. 3c). A significant reduction was not observed in the corresponding SS1 control oligodeoxynucleotidetreated blastocysts, which had similar ISP1 transcript content to untreated controls. AS1 oligodeoxynucleotidetreated blastocysts also displayed reduced strypsin activity compared with untreated or control oligodeoxynucleotidetreated blastocysts. In control oligonucleotide-treated blastocysts (Fig. 5d), localized strypsin activity was observed histochemically at the abembryonic pole of blastocysts. In contrast, strypsin activity was absent in antisense oligodeoxynucleotide-treated blastocysts (Fig. 5e). Consistent with our hypothesis, this observation indicates that the ISP1 gene probably encodes the strypsin activity that is responsible for hatching. 
ISP1

MMCP-6

HumTRYP1

RMCP-7

Chymotrypsin

MusELAST2

ISP1

MMCP-6

HumTRYP1

RMCP-7

Chymotrypsin

MusELAST2

ISP1

MMCP- 6

HumTRYP1

RMCP-7

Chymotrypsin

MusELAST2

ISP1

MMCP-6

HumTRYP1

RMCP-7

Chymotrypsin

MusELAST2

ISP1

MMCP-6

HumTRYP1

RMCP-7

Chymotrypsin

MusELAST2

1 - - MFRLLLLALSCLESTVFMASVSISRSKPVEIV

MLKRRILLIWALV PANQRVGIVGGHEASESKWPWQVSLRFK-- - LNY LILIA PVLASRAYAA PA PVQALQQAG I VGGQEAPR SKWPWQVSLRVR - - DRY - - -MLKLLLLTLPLLSS L VHAA PS - - LAMPREG I VGGQEASGNKW PWQVS L R VN - - - DTY 作 1 - - MIRTLLLSALVAGALSCGYPRYEVEDDVSR VVGGQEATPNTWPWQVSLQVLS - SGR

58 WVHICGGSIIHPQWILTAAHCIQSQDADPAVYRVQVGEVYLYKEQELLTISRIIIHPDYN 56 WIHFCGGSLIH PQWVLTAAHCVGPHIKSPQLFRVQLREQYLYYGDQLLSLNR IVVH PHYY 55 WMH FCGGSL I P QWVLTAAHCLG PDVKDLATLRVQLREQHLYYQDQLLPVSR I IVH PQFY 53 WMH FCGG-SI H P QWVLTAAHCVG PNKAD PNKLRVQLRKQ Y LYYHDHLLTVSQI ISH PDFY 39 WRHTC GGTLIASNFVLTAAHCISNTWTYRVAVGKNNLEVEDEEGSLFVGVDTIHVHKRWN 56 WRHNCGGSLVANNWVLTAAHCLSNYQTYRVLLGAHSLSNPG-AGSAAVQVSKLVVHQRWN

\section{rar}

118 DVSKRF - -DLALMOLTALLVTSTNVS PVSL PKDSSTFDSTDOCWLVGWGNLLORVPLOP P

116 TAEGGA- - DVALLELEVPVNVSTHIFP IS L P PAS ET F PPGT SCWVT GWGDIDNDEP L P P P

115 IIQTGA--DIALLELEEPVNISSRVHTVMLP PASET F P PGMPCWVT GWGDVDNDEPLP P P

112 IAODGA-DIALLKLTNPVNITSNVHTVSLP PASETFPSGTLCWVT GWGNINNDVSLP P P

99 ALLLRN--DIALTKLAEHVELSDTIQVACL PEKDSLLPKDY PCYVTGWGRLWTNGPIAD115 SQNVGNGYDIALIKLA SPVTLSKNIQTACL P AGTILPRNYVCYVTGWGLLQTNGNSPD-

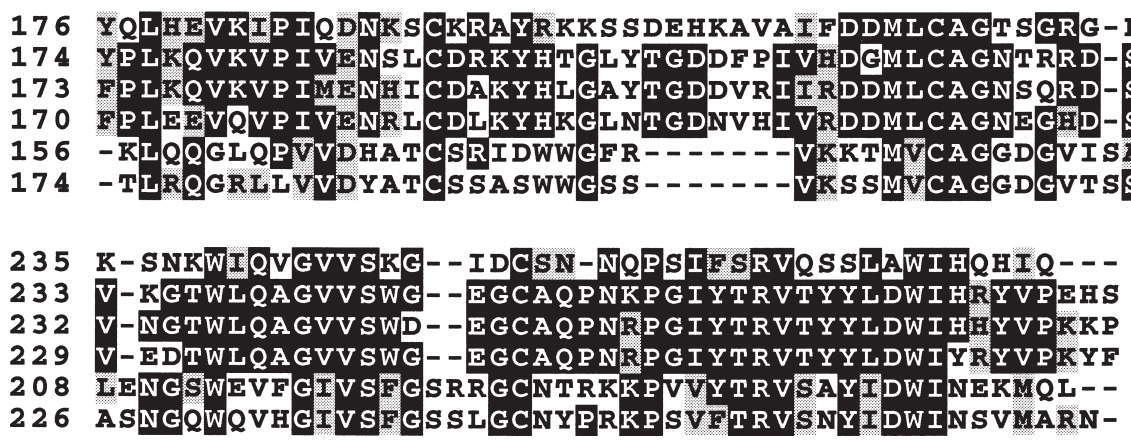

Fig. 2. Predicted amino acid sequence for murine implantation serine proteinase 1 (ISP1) and alignment with related serine proteinases. Identical amino acids are marked by black boxes and conservative substitutions are noted by grey boxes. ISP1 is most similar to mouse mast cell proteinase (MMCP-6) with which it shares $45 \%$ identity. Chymotrypsin and murine elastase (MusELAST2) both share 38\% identity with ISP1. Arrows indicate predicted pre- and pro-cleavage sites. The S1 proteinase active site consensus sequences His ([LIVM]-[ST]-A-[STAG]-H-C) and Ser [DNSTAGC]-[GSTAPIM VQH]-x(2)-G-[DE]-S-G-[GS]-[SAPHV]-[LIVMFYWH][LIVMF YSTANQH]) are underlined. HumTRYP1: human tryptase 1; RMCP-7: rat mast cell proteinase 7.

\section{Antisense disruption of hatching in vitro}

Blastocysts treated with the antisense oligodeoxynucleotides displayed a considerable impairment in hatching over time (Table 1; Fig. 6). Compared with oligodeoxynucleotide-treated and untreated controls, a significant percentage of antisense oligodeoxynucleotidetreated blastocysts did not hatch. Other treated blastocysts displayed a delay in hatching, indicating that antisense treatment could transiently inhibit hatching until the concentration of oligodeoxynucleotide in the media decreased.

Control oligodeoxynucleotide-treated blastocysts developed and hatched normally (Fig. 5a), mirroring untreated blastocysts that were cultured in parallel (not shown). Starting at about $20 \mathrm{~h}$, the zona pellucida became thin and the blastocysts emanated through ruptures at the abembryonic pole. In contrast, most of the antisense oligodeoxynucleotide-treated blastocysts grew until they compressed and thinned the zona pellucida wall (Fig. 5c), but were unable to cause it to rupture. After $60 \mathrm{~h}$ trapped inside the zona pellucida, antisense-treated blastocysts began to die and shrink away from the wall (Fig. 5b).

\section{Antisense disruption of blastocyst invasion}

As ISP1 gene expression had been observed previously during blastocyst outgrowth in vitro, an attempt was made to prevent blastocyst outgrowth after hatching had occurred (Fig. 7). Control oligodeoxynucleotide-treated blastocysts adhered to and invaded extracellular matrix after 2 days in culture, not unlike untreated control blastocysts (Fig. 7a,b). ISP1 antisense oligodeoxynucleotide-treated blastocysts took 5 days to adhere to the matrix, but growth was so delayed that the blastocysts never reached the size or extent of the outgrowth observed with control embryos (Fig. 7c,d). This observation indicates that ISP1 expression is probably also vital for the initiation of blastocyst attachment to 
(a)

(b)

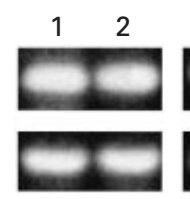

3

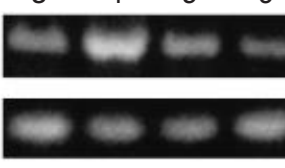

(c)

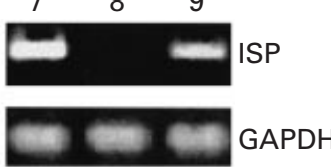

Fig. 3. Implantation serine proteinase 1 (ISP1) gene expression in preimplantation mouse embryos. ISP1 and GAPDH gene expression in early embryos (approximately $n=100$ ) were detected by RT-PCR. (a) ISP1 gene expression in blastocysts undergoing hatching (lane 1) or outgrowth (lane 2) in vitro. (b) ISP1 transcripts in preimplantation embryos collected as zygotes (lane 3), morulae (lane 4) and blastocysts (lane 5), in addition to implantation sites (lane 6). (c) ISP1 gene expression in blastocysts at day 3.0 before exposure to antisense oligodeoxynucleotides (lane 7). ISP1 transcripts were not detected in blastocysts treated for $8 \mathrm{~h}$ in medium containing $2.5 \mu \mathrm{mol}$ antisense oligodeoxynucleotide $\mathrm{I}^{-1}$ (lane 8), but were detected in blastocysts cultured in the presence of $2.5 \mu \mathrm{mol}$ control oligodeoxynucleotide $\mathrm{I}^{-1}$ (lane 9).

extracellular matrix and subsequent outgrowth during implantation.

\section{Discussion}

In this study, a novel serine proteinase gene, ISP1, has been cloned by virtue of its expression at the day 6.5 implantation site. Previously, serine proteinase active site RT-PCR of RNA derived from preimplantation embryos identified hepsin, a membrane-associated serine proteinase also expressed in kidney and liver. Hepsin was proposed initially to represent the mammalian hatching enzyme $(\mathrm{Vu}$ et al., 1997), but this possibility was ruled out in subsequent gene disruption studies (Wu et al., 1998). Interestingly, ISP1 was not identified in this previous search for preimplantation serine proteinases. Similarly, hepsin was not identified in the screen in the present study, although it is not known whether this serine proteinase is expressed during implantation. Nonetheless, based on the distinction of the degenerate primers used in both studies, the possibility exists that additional serine proteinases involved in implantation may be identified (for example, O'Sullivan et al., in press).

ISP1 is expressed during blastocyst hatching and outgrowth. On the basis of this expression and the similarity of tryptases to trypsin, it was hypothesized that ISP1 encodes the trypsin-like activity, strypsin, that was first identified in blastocyst hatching by Perona and Wassarman (1986). In agreement with this hypothesis, two antisense oligodeoxynucleotides targeted against ISP1 are able to specifically interfere with blastocyst hatching in vitro in a concentration- and time-dependent manner. Over time, it was observed that some blastocysts are able to escape hatching arrest, presumably due to degradation of oligodeoxynucleotide within culture media. Indeed, if oligodeoxynucleotides were administered in fresh medium over time, a prolonged interference on hatching was observed (C. M. O'Sullivan, unpublished). Similarly, fresh oligodeoxy-
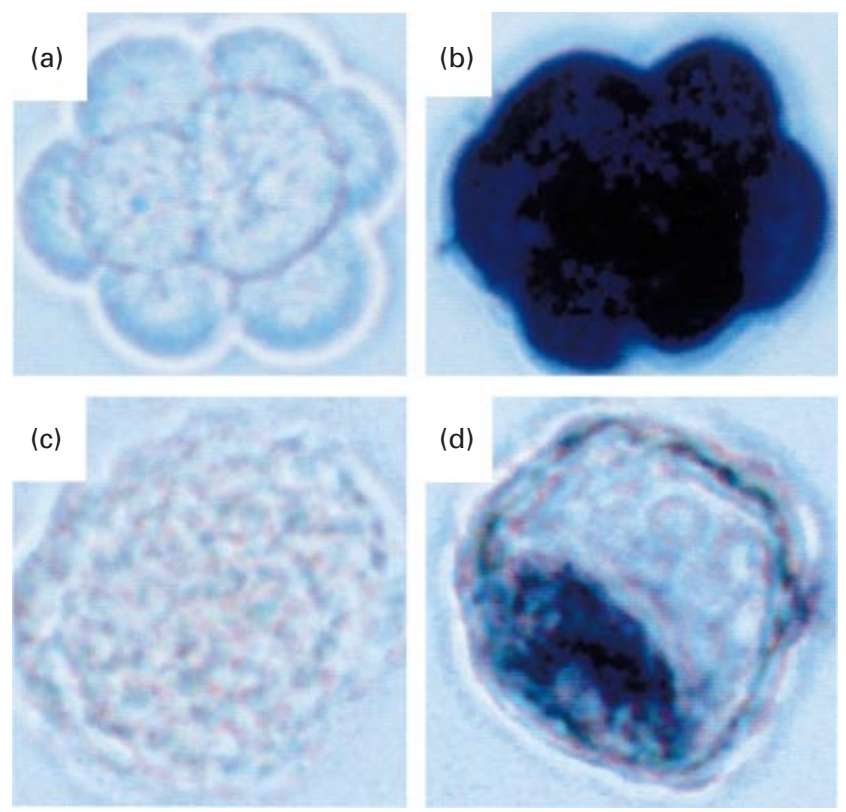

Fig. 4. Expression of the murine implantation serine proteinase 1 (ISP1) gene in morulae and blastocysts. (a,b) Morulae and (c,d) blastocysts were stained using whole mount in situ hybridization with $(a, c)$ sense and $(b, d)$ antisense ISP1 probes. $(a, c)$ Staining is not observed using the sense probe as a control. (b) Intense ISP1 expression is observed in all of the blastomeres of the morula. (d) In the blastocyst, ISP1 gene expression occurs within the trophoblast and inner cell mass. Equivalent staining is observed, although monolayer trophoblast staining appears weaker than that of the multilayer inner cell mass.

nucleotide medium was required to affect blastocyst outgrowth over 5 days. If oligodeoxynucleotides are allowed to dissipate in medium, blastocysts are able to escape the block on outgrowth (C. M. O'Sullivan, unpublished). The observation that blastocysts can escape hatching and outgrowth arrest indicates that the antisense oligodeoxynucleotides are not toxic. Indeed, blastocysts do not die as a consequence of antisense oligodeoxynucleotide treatment (C. M. O'Sullivan, unpublished). However, embryonic death does occur when blastocysts fail to hatch or outgrow after a period of time.

Antisense oligodeoxynucleotides that are targeted against the initiation codon of mRNAs interfere with translation and result in the degradation of target transcripts (Schlingensiepen and Brysch, 1992). Antisense oligodeoxynucleotide treatment of ISP1 specifically blocks the accumulation of ISP1 mRNA in blastocysts $8 \mathrm{~h}$ after treatment. As with our observations on hatching, this blockage is transient, as ISP1 mRNA content returns almost to normal after $24 \mathrm{~h}$ of treatment (data not shown). After $24 \mathrm{~h}$ of antisense oligodeoxynucleotide treatment, strypsin activity was absent at the abembryonic pole.

As the ISP1 gene is expressed throughout the blastocyst and strypsin activity is localized extracellularly to the distal pole of the blastocyst, these results indicate that ISP1 

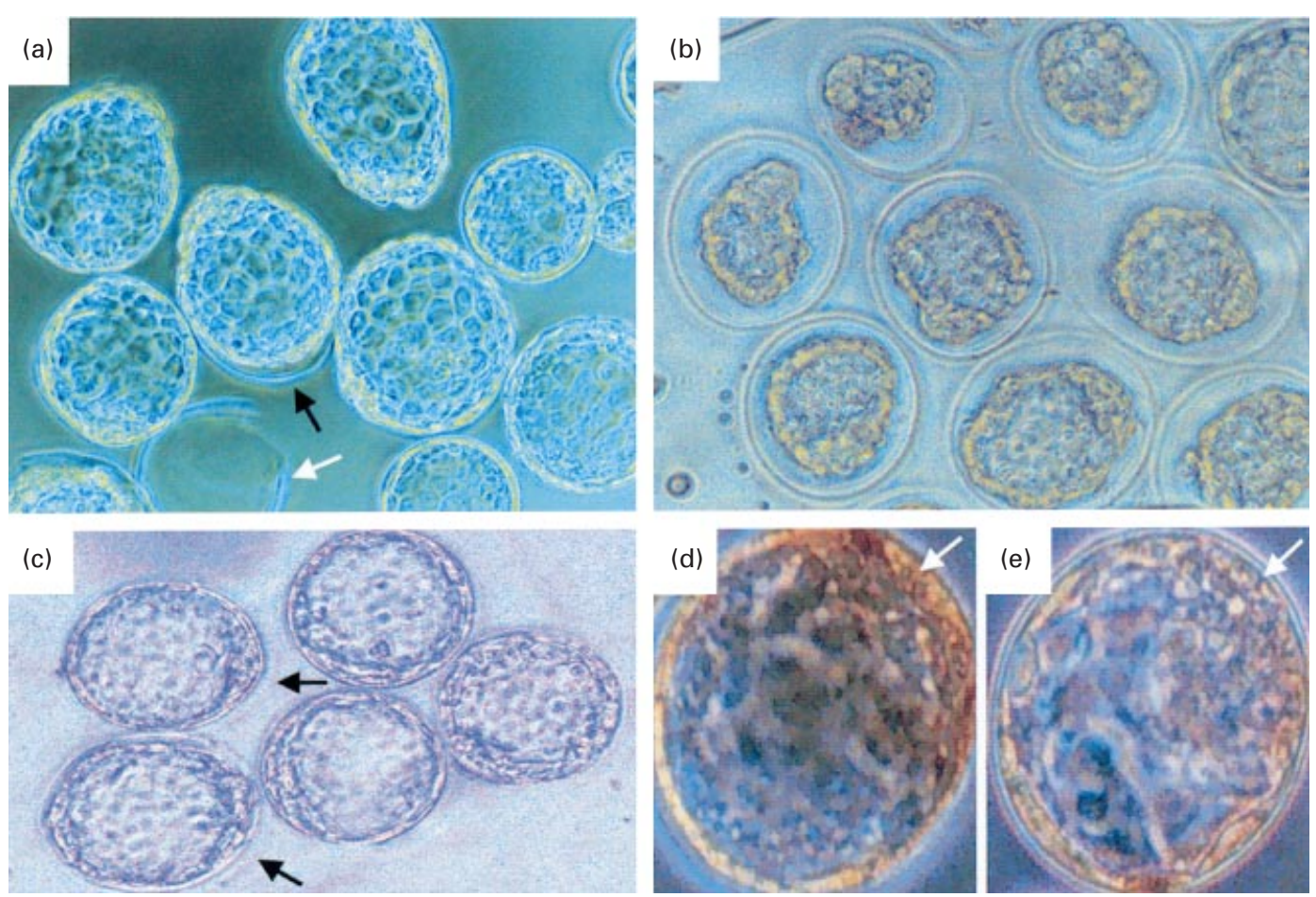

Fig. 5. Murine implantation serine proteinase 1 (ISP1) antisense oligodeoxynucleotides inhibit murine blastocyst hatching and strypsin histochemical staining in vitro. (a) Control oligodeoxynucleotide-treated blastocysts showing successfully hatched blastocysts. As the zona pellucida becomes thinner, the blastocyst emerges through a small rupture that forms on the abembryonic pole at hatching. The black arrow represents a blastocyst in the middle of hatching. The white arrow shows an empty cask after hatching. (b) Antisense oligodeoxynucleotide-treated blastocysts showing degenerated embryos one day after failing to hatch. Note that in these embryos the zona pellucida is thickened. (c) One day earlier, the same embryos as in (b) developed normally until they were pressed against the zona pellucida. The black arrows show the very thin zonae pellucidae that occur when blastocysts are fully expanded, but fail to hatch in the presence of ISP1 antisense oligonucleotides. (d) Control oligodeoxynucleotide-treated blastocysts showing normal strypsin activity staining. The histochemical stain is concentrated at the abembryonic pole (white arrow). (e) Antisense oligodeoxynucleotide-treated blastocysts display little strypsin activity at the abembryonic pole (white arrow).

Table 1. Percentage of unhatched mouse blastocysts after oligodeoxynucleotide administration

\begin{tabular}{lrrrr}
\hline & \multicolumn{4}{c}{$\begin{array}{c}\text { Percentage hatched after } \\
\text { time (of 100 blastocysts) }\end{array}$} \\
\cline { 2 - 5 } Oligodeoxynucleotide & $20 \mathrm{~h}$ & $30 \mathrm{~h}$ & $40 \mathrm{~h}$ & $60 \mathrm{~h}$ \\
\hline Blank & 10 & 30 & 65 & 80 \\
SS1 $\left(2.5 \mu \mathrm{mol} \mathrm{I}^{-1}\right)$ & 10 & 16 & 58 & 90 \\
AS1 $\left(2.5 \mu \mathrm{mol} \mathrm{I}^{-1}\right)$ & 0 & 0 & 16 & 37 \\
AS2 $\left(2.5 \mu \mathrm{mol} \mathrm{I}^{-1}\right)$ & 0 & 20 & 35 & 40 \\
SS1 $\left(5.0 \mu \mathrm{mol} \mathrm{I}^{-1}\right)$ & 10 & 39 & 61 & 77 \\
AS1 $\left(5.0 \mu \mathrm{mol} \mathrm{I}^{-1}\right)$ & 10 & 10 & 20 & 20 \\
AS2 $\left(5.0 \mu \mathrm{mol} \mathrm{I}^{-1}\right)$ & 0 & 5 & 35 & 45 \\
\hline
\end{tabular}

SS1 is a scrambled sense oligodeoxynucleotide of DNA sequence surrounding the initiation codon of implantation serine proteinase 1 (ISP1). AS1 and AS2 are antisense oligodeoxynucleotides surrounding the initiation codon of ISP1 covering the region immediately upstream (AS1) and downstream (AS2).

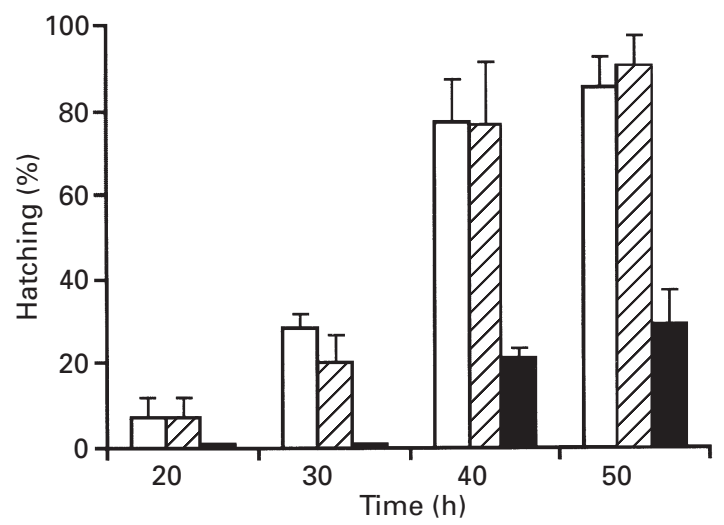

Fig. 6. Mouse implantation serine proteinase 1 (ISP1) antisense oligonucleotides inhibit blastocyst hatching in a time dependent manner. One hundred blastocysts (day 3.5 of embryo development) were cultured in the presence of water $(\square), 2.5 \mu \mathrm{mol}$ scrambled sense SS1 oligodeoxynucleotide $\mathrm{l}^{-1}(\square)$ or antisense AS1 oligodeoxy-

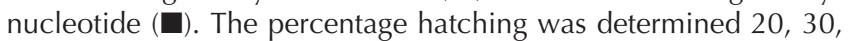
40 and $60 \mathrm{~h}$ after addition of oligodeoxynucleotide. Values are mean $\pm \mathrm{SE}(n=3)$. 

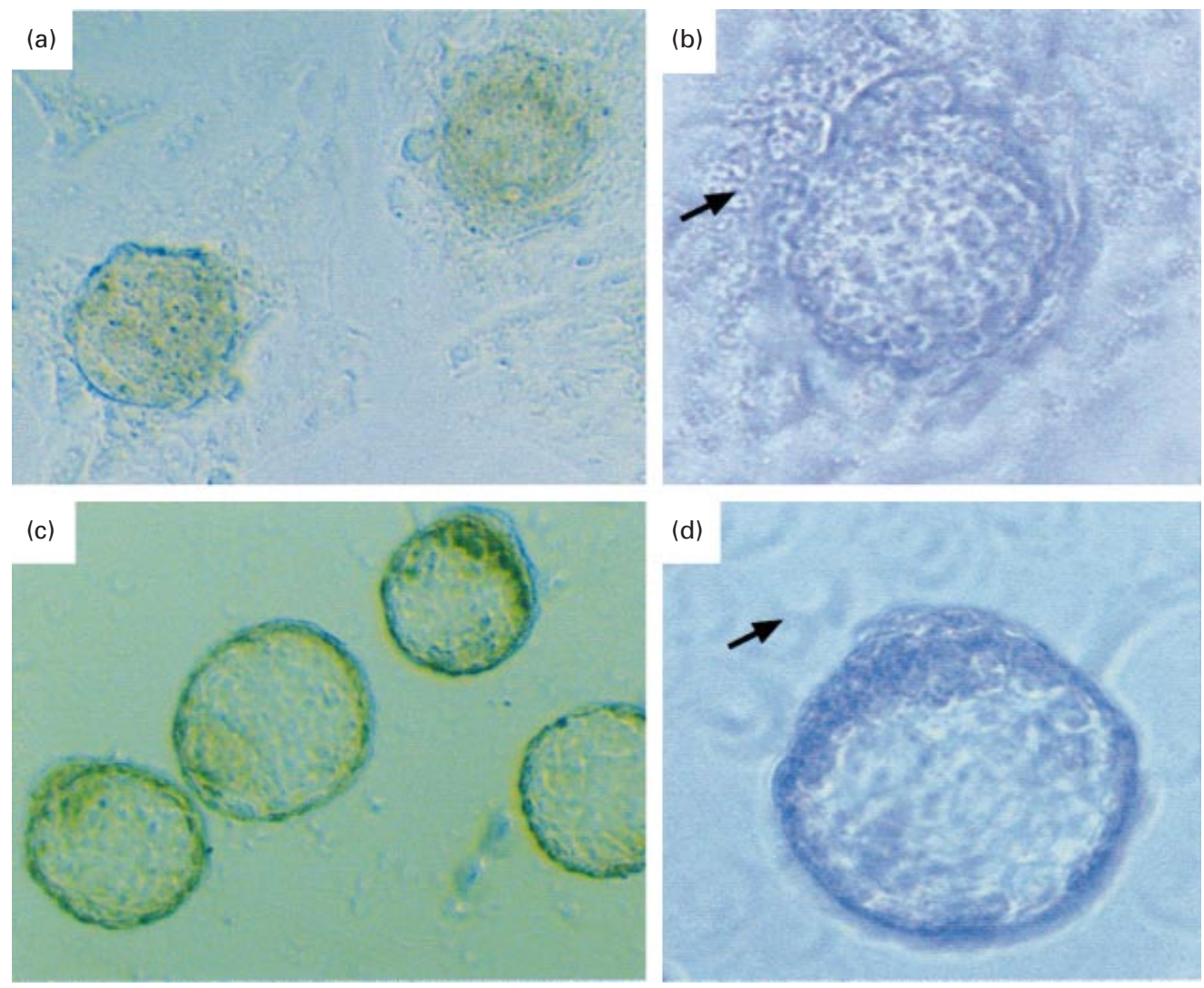

Fig. 7. Murine implantation serine proteinase 1 (ISP1) antisense oligodeoxynucleotides inhibit mouse blastocyst outgrowth onto extracellular matrix in vitro. (a) Prehatched blastocyst treated with a control oligodeoxynucleotide invades normally into extracellular matrix. (b) A control oligonucleotide-treated blastocyst, showing invading trophoblasts (black arrow). (c) Prehatched blastocyts treated with antisense oligodeoxynucleotide fail to invade into extracellular matrix and do not develop beyond the blastocyst stage. (d) A blastocyst failing to invade; invading trophoblasts are not apparent. The refraction of light that is noticed (arrow) is from the extracellular matrix previously laid down on these dishes.

protein is either recruited to the abembryonic pole for activity or is translated preferentially in apical trophoblasts. A significant reduction of localized strypsin activity in blastocysts was observed consistently when ISP1 mRNA accumulation was abrogated. The predicted molecular mass of ISP1 (approximately $27000 \mathrm{Da}$ ) is considerably smaller than the native molecular mass of strypsin $(74000 \mathrm{Da})$, a finding which indicates that ISP1 must probably multimerize for activity. Indeed, tryptases including mouse mast cell proteinases multimerize for activity and are assembled with the assistance of heparin sulphate proteoglycans (Lindstedt et al., 1998; Huang et al., 2000). Consistent with this idea of ISP1/strypsin assembly, the abembryonic pole of the blastocyst is rich in heparin sulphate proteoglycan (Farach et al., 1987). As heparinase digestion has demonstrated a requirement for this heparin sulphate bed in blastocyst attachment and outgrowth (Farach et al., 1987), it is likely that this bed is also required for hatching. Similarly, the actions of maternal heparin sulphate binding-EGF in stimulating blastocyst hatching and outgrowth may be explained by the $\mathrm{pH}$ dependence of tryptase activation (Lindstedt et al., 1998; Huang et al., 2000) and the changes in ion flux that occur downstream of HB-EGF binding to the ErbB4 receptor (Wang et al., 2000).

Owing to the difficulty in cloning and characterizing strypsin, the importance of strypsin in facilitating the hatching process has recently been considered less important than blastocyst growth and equally ill-defined uterine 'lysins' in promoting zona pellucida thinning (Montag et al., 2000). Recent studies suggest that the 'focal' hatching that occurs in vitro is distinct from hatching in utero, in which the zona pellucida appears to 'dissolve' after thinning (Gonzales and Bavinster, 1995; Montag et al., 2000; Gonzales et al., 2001). As hatching occurs approximately 1 day earlier in utero than in vitro, Gonzales and Bavinster (1995) have described hatching in vitro as an artefact characterized by the absence of a uterine 'lysin proteinase'. Indeed, there is evidence to suggest that a hormonally regulated proteinase associated with uterine secretions may also contribute to hatching (Orsini and McLaren, 1967; 
Joshi and Murray, 1974; Rosenfeld and Joshi, 1981) and that this proteinase is regulated by progesterone (Denker, 1977). O'Sullivan et al. (in press) describe the cloning and characterization of the ISP2 gene, which encodes a strypsin homologue that is expressed in the endometrial glands during early pregnancy. As this gland provides the major source of uterine secretions during implantation and the ISP2 gene is expressed in a progesterone-dependent manner, it is speculated that ISP2 may encode a uterine lysin, which extrinsically facilitates blastocyst hatching.

The existence of uterine proteinases associated with zona lysis in vivo does not minimize the importance of strypsin in blastocyst hatching, as it has been demonstrated that strypsin is necessary and sufficient to effect hatching in vitro. However, strypsin may play a secondary role in hatching in utero and serve as a contingency factor for failed zona pellucida lysis. Hence, similar to the observations on implantation, genetic redundancy may also be operating in blastocyst hatching to ensure that a successful pregnancy is generated.

The ISP1 mRNA knockdown experiments have helped to clarify the mechanism of hatching. During the antisense experiments, zona pellucida thinning was observed in conjunction with blastocyst growth. However, when blastocysts failed to hatch and died within the zona pellucida, regression of the embryo resulted in a reversal of zona pellucida thinning. This observation confirms the hypothesis that zona pellucida thinning is dependent on blastocyst expansion but indicates that proteinases may not be involved in thinning. Nonetheless, blastocyst growth and zona pellucida thinning may play an important regulatory role in ensuring that hatching occurs at an appropriate time, by exposing lysin- or strypsin-specific proteolytic sites within this proteinaceous sheath.

After Mintz (1972) and Pinsker et al. (1974) first suggested that the enzyme responsible for hatching might also be an implantation initiation factor, Gonzales and Bavinster (1995) predicted that the enzyme responsible for focal hatching in vitro might really be the enzyme responsible for facilitating blastocyst attachment and invasion. Through our discovery of ISP1, we have confirmed this additional role for the hatching enzyme in facilitating implantation competence. Indeed, the abembryonic pole of the blastocyst becomes competent to attach and invade into extracellular matrix in vitro, and this competence occurs as a function of localized heparin sulphate proteoglycan and the action of heparin binding EGF (Farach et al., 1987; Das et al., 1994). ISP1/strypsin may participate in a continuum that connects blastocyst hatching to extracellular matrix attachment and outgrowth. Historically, hatching and outgrowth have been viewed as unrelated molecular events. Although serine proteinase inhibitors affect both hatching (Perona and Wassarman, 1986) and outgrowth (Kubo et al., 1981; Behrendtsen et al., 1992), these studies have focused on the respective roles of strypsin in hatching and UPA in outgrowth. We note that most, if not all, of these inhibitors, including bis[5-amido-2-benzimidazole], are effective against tryptases (Compton et al., 1998; Sanderson, 1999) and suggest that their action in affecting outgrowth may have been directed to the extracellular matrix degrading potential of ISP1/strypsin.

With hindsight, it seems reasonable that a localized proteinase involved in degrading the zona pellucida might also be involved in initiating the degradation of extracellular matrix that occurs in blastocyst outgrowth. ISP1/ strypsin may also participate indirectly in extracellular matrix degradation through the activation of other proteinases such as MMP-9, which is activated by tryptases in vivo (Keski-Oja et al., 1992; Lohi et al., 1992). Although removal of the zona pellucida barrier has long been viewed as the critical first step in implantation, the results of the present study demonstrate that the role of the hatching proteinase in implantation may be more active than passive. On the basis of its early expression, ISP1/strypsin may be a lynch pin in the cascade of proteinase activity during implantation. Hence, further investigation into the function of ISP1/strypsin in vivo is warranted.

The role of the hatching proteinase in facilitating embryo attachment and outgrowth may also serve to explain why assisted hatching procedures performed in fertility clinics have failed to promote the successful implantation of human embryos (for review see De Vos and Van Steirteghem, 2000). Indeed, embryos from women of advanced age frequently fail to hatch in vitro and may be devoid of hatching enzyme activity (Bider et al., 1997). Having identified the mouse ISP1 gene, an important diagnostic tool in human fertility may result, while physical preparations of ISP1/strypsin may potentially be used to improve the success of assisted reproduction.

The authors would like to thank G. Bain, J. Cross, D. Edwards, M. Hollenberg, J. McGhee, R. Pon and G. Schultz for their advice and comments. B. Carson, E. Rattner and J. Turnbull provided technical assistance. This work was funded by the Alberta Cancer Board and the Canadian Institutes of Health Research (Operating Grant no 14702). C. M. O'Sullivan is supported by an Alberta Cancer Board Studentship and by The William H. Davies Scholarship (University of Calgary). D. E. Rancourt is a scholar of the Alberta Heritage Foundation for Medical Research. Accessation no AF184895.

\section{References}

Afonso S, Romagnano L and Babiarz B (1997) The expression and function of cystatin $C$ and cathepsin B and cathepsin L during mouse embryo implantation and placentation Development 124 3415-3425

Alexander CM, Hansell EJ, Behrendsten O, Flannery ML, Kishani NS, Hawkes SP and Werb Z (1996) Expression and function of matrix metalloproteinases and their inhibitors at the maternal-embryonic boundary during mouse embryo implantation Development 122 1723-1736

Altschul SF, Madden TL, Schaffer AA, Zhang J, Zhang Z, Miller W and Lipman DJ (1997) Gapped BLAST and PSI-BLAST: a new generation of protein database search programs Nucleic Acids Research 25 3389-3402

Arcellana-Panlilio MY and Schultz GA (1993) Analysis of messenger RNA Methods in Enzymology 225 303-328

Behrendtsen O, Alexander CM and Werb Z (1992) Metalloproteinases 
mediate extracellular matrix degradation by cells from mouse blastocyst outgrowths Development 114 447-456

Behrendtsen O, Alexander CM, and Werb Z (1995) Cooperative interactions between extracellular matrix, integrins and parathyroid hormonerelated peptide regulate parietal endoderm differentiation in mouse embryos Development 121 4137-4148

Bider D, Livshits A, Yonish M, Yemini Z, Mashiach S and Dor J (1997) Assisted hatching by zona drilling of human embryos in women of advanced age Human Reproduction 12 317-320

Carmeliet P, Schoonjans L, Kieckens L et al. (1994) Physiological consequences of loss of plasminogen activator gene function in mice Nature 368 419-424

Carson DD, Tang JP and Julian J (1993) Heparin sulfate proteoglycan (perlecan) expression by mouse embryos during acquisition of attachment competence Developmental Biology 155 97-106

Carson DD, Bagchi I, Dey SK, Enders AC, Fazleabas AT, Lessey BA and Yoshinaga K (2000) Embryo implantation Developmental Biology 223 217-237

Compton SJ, Cairns JA, Holgate ST and Walls AF (1998) The role of mast cell tryptase in regulating endothelial cell proliferation, cytokine release, and adhesion molecule expression: tryptase induces expression of mRNA for IL-1 beta and IL-8 and stimulates the selective release of IL-8 from human umbilical vein endothelial cells Journal of Immunology 161 1939-1946

Das SK, Wang XN, Paria BC, Damm D, Abraham JA, Klagsbrun M, Andrews GK and Dey SK (1994) Heparin-binding EGF-like growth factor gene is induced in the mouse uterus temporally by the blastocyst solely at the site of its apposition: a possible ligand for interaction of blastocyst EGF receptor in implantation Development 120 1071-1083

Denker HW (1977) Implantation: the role of proteinases and blockage of implantation by proteinase inhibitors Advances in Anatomy, Embryology and Cell Biology 53 3-123

De Vos A and Van Steirteghem A (2000) Zona hardening, zona drilling and assisted hatching: new achievements in assisted reproduction Cells Tissues and Organs 166 220-227

Erbach GT, Lawitts JA, Papaioannou VE and Biggers JD (1994) Differentia growth of the mouse preimplantation embryo in chemically defined media Biology of Reproduction 50 1027-1033

Farach MC, Tang JP, Decker GL and Carson DD (1987) Heparin/heparin sulfate is involved in attachment and spreading of mouse embryos in vitro. Developmental Biology 123 407-410

Gonzales DS and Bavinster BD (1995) Zona pellucida escape by hamste blastocysts in vitro is delayed and morphologically different compared to zona escape in vivo. Biology of Reproduction 52 470-480

Gonzales DS, Bavinster BD and Mese SA (2001) In utero and in vitro proteinase activity during the Mesocricetus auratus embryo zona escape time window Biology of Reproduction 64 222-230

Harvey MB, Leco KJ, Arcellana-Panillo MY, Zhang X, Edwards DR and Schultz GA (1995) Proteinase expression in early mouse embryos is regulated by leukaemia inhibitory factor and epidermal growth factor Development 121 1005-1014

Higgins DG (1994) CLUSTAL V: multiple alignment of DNA and protein sequences Methods in Molecular Biology 25 307-318

Hogan B, Beddington R, Costantini F and Lacy E (1994) Manipulating the Mouse Embryo: A Laboratory Manual. Cold Spring Harbor Laboratory Press, Cold Spring Harbor, New York

Huang C, Morales G, Vagi A et al. (2000) Formation of enzymatically active, homotypic, and heterotypic tetramers of mouse mast cell tryptases. Dependence on a conserved Trp-rich domain on the surface Journal of Biological Chemistry 275 351-358

Hwang S, Lee E, Chung Y, Yoon BK, Lee JH and Choi D (2000) Intactness of zona pellucida does not affect the secretion of a trypsin-like protease from mouse blastocyst Journal of Korean Medical Science 15 529-532

Jones DH, Davies TC and Kidder GM (1997) Embryonic expression of the putative gamma subunit of the sodium pump is required for acquisition of fluid transport capacity during mouse blastocyst development Journal of Cell Biology 139 1545-1552

Joshi MS and Murray IM (1974) Immunological studies of the rat uterine fluid peptidase Journal of Reproduction and Fertility 37 361-365

Keski-Oja J, Lohi J, Tuuttila A, Tryggvason K and Vartio T (1992) Proteolytic processing of the 72,000-Da type IV collagenase by urokinase plasminogen activator Experimental Cell Research 202 471-476

Kirby DR, Potts DM and Wilson IB (1967) On the orientation of the implanting blastocyst Journal of Embryology and Experimental Morphology 17 527-532

Kubo H, Spindle A and Pederson RA (1981) Inhibition of mouse blastocyst attachment and outgrowth by protease inhibitors Journal of Experimental Zoology 216 445-451

Lefebvre O, Regnier C, Chenard MP, Wendling C, Chambon P, Basset $\mathbf{P}$ and Rio MC (1995) Developmental expression of mouse stromelysin 3 mRNA Development 121 947-955

Lindstedt KA, Kokkonen JO and Kovanen PT (1998) Regulation of the activity of secreted human lung mast cell tryptase by mast cell proteoglycans Biochimica et Biophysica Acta 1425 617-627

Lohi J, Harvima I and Keski-Oja J (1992) Pericellular substrates of human mast cell tryptase: 72,000 dalton gelatinase and fibronectin Journal of Cell Biology $\mathbf{5 0} 337-349$

Lutzelschwab C, Pejler G, Aveskogh M and Hellman L (1997) Secretory granule proteases in rat mast cells. Cloning of 10 different serine proteases and carboxypeptidase $\mathrm{A}$ from various rat mast cell populations Journal of Experimental Medicine 185 13-29

Mintz B (1972) Implantation initiating factor from mouse uterus. In Biology of Mammalian Fertilization and Implantation pp 343-356 Eds KS Moghissi and ES Hafz. Thomas Springfield, Illinois

Montag M, Koll B, Holmes P and van der Ven H (2000) Significance of the number of embryonic cells and the state of the zona pellucida for hatching in mouse blastocysts in vitro versus in vivo. Biology of Reproduction $\mathbf{6 2}$ 1738-1744

Orsini MW and McLaren A (1967) Loss of the zona pellucida in mice, and the effect of tubal ligation and ovariectomy Journal of Reproduction and Fertility 13 485-499

O'Sullivan CM, Liu SY, Rancourt SL and Rancourt DE Regulation of the strypsin-related proteinase, ISP2, by progesterone in endometrial gland epithelium during implantation Reproduction (in press)

Paria BC, Elenius K, Klagsbrun M and Dey SK (1999) Heparin-binding EGFlike growth factor interacts with mouse blastocysts independently of ErbB1: a possible role for heparin sulfate proteoglycans and ErbB4 in blastocyst implantation Development 126 1997-2005

Perona RM and Wassarman PM (1986) Mouse blastocysts hatch in vitro by using a trypsin-like proteinase associated with cells of mural trophoectoderm Developmental Biology 114 42-52

Pinsker MC, Sacco AG and Mintz B (1974) Implantation associated proteinase in mouse uterine fluid Developmental Biology 38 285-290

Prendergast JA, Pinkoski M, Wolfenden A and Bleackley RC (1991) Structure and evolution of the cytotoxic cell proteinase genes CCP3, CCP4 and CCP5 Journal of Molecular Biology 220 867-875

Raab G, Kover K, Paria BC, Dey SK, Ezzell RM and Klagsbrun M (1996) Mouse preimplantation blastocysts adhere to cells expressing the transmembrane form of heparin-binding EGF-like growth factor Development 122 637-645

Rancourt SL and Rancourt DE (1997) Murine subtilisin-like proteinase SPC6 is expressed during embryonic implantation, somitogenesis and skeletal formation Developmental Genetics 21 75-81

Rinkenberger JL, Cross JC and Werb Z (1997) Molecular genetics of implantation in the mouse Developmental Genetics 21 6-20

Rosenfeld MG and Joshi MS (1981) Effect of a rat uterine fluid endopeptidase on lysis of the zona pellucida Journal of Reproduction and Fertility 62 199-203

Sambrook J, Fritsch EF and Maniatis T (1989) Molecular Cloning: A Laboratory Manual. Cold Spring Harbor Laboratory Press, Cold Spring Harbor, New York

Sanderson PE (1999) Small, noncovalent serine protease inhibitors Medical Research Reviews 19 179-197

Sawada H, Yamazaki K and Hoshi M (1990) Trypsin-like hatching protease from mouse embryos: evidence for the presence in culture media and its enzymatic properties Journal of Experimental Zoology 254 83-87

Schlingensiepen KH and Brysch W (1992) Phosphorothioate oligomers: inhibitors of oncogene expression in tumor cells as a tool for gene function analysis. In Gene Regulation: Biology of Antisense RNA and 
DNA pp 317-328 Eds R Erickson and J Izant. Raven Press, New York Smyth MJ, O'Conner MD and Trapani JA (1996) Granzymes: a variety of serine protease specificities encoded by genetically distinct subfamilies Journal of Leukocyte Biology 60 555-562

Teesalu T, Blasi F and Talarico D (1996) Embryo implantation in mouse: fetomaternal coordination in the pattern of expression of UPA, UPAR, PAI-1 and $\alpha 2 \mathrm{MR} / \mathrm{LRP}$ genes Mechanisms of Development 56 103-116

Vu TH, Liu RW, Haaksma CJ, Tomasek JJ and Howard EW (1997) Identification and cloning of the membrane-associated serine proteinase, hepsin, from mouse preimplantation embryos Journal of Biological Chemistry 272 31315-31320

Vu TH, Shipley JM, Bergers G, Berger JE, Helms JA, Hanahan D, Shapiro SD, Senior RM and Werb Z (1998) MMP-9/gelatinase B is a key regulator of growth plate, angiogenesis and apoptosis of hypertrophic chondrocytes Cel/ 93 411-422

Wang J, Mayernik L, Schultz JF and Armant DR (2000) Acceleration of trophoblast differentiation by heparin-binding EGF-like growth factor is dependent on the stage-specific activation of calcium influx by ErbB receptors in developing mouse blastocysts Development 127 33-44

Werb Z, Alexander CM and Adler RR (1992) Expression and function of matrix metalloproteinases in development Matrix 1 337-343

Wu Q, Yu D, Post J, Halks-Miller M, Sadler JE and Morser J (1998) Generation and characterisation of mice deficient in hepsin, a hepatic transmembrane serine protease Journal of Clinical Investigation 101 $321-326$

Received 15 January 2001.

First decision 20 February 2001.

Accepted 27 March 2001. 